\title{
SERABUT KELAPA SEBAGAI PRODUK BODY PROTECTOR YANG ERGONOMIS DENGAN METODE BIO-SIZING
}

\author{
Iftitah Ruwana dan Dayal Gustopo \\ Institut Teknologi Nasional Malang \\ e-mail: ita_ruwana@yahoo.com
}

\begin{abstract}
ABSTRAK
Serat alam yang berasal dari serabut kelapa banyak tumbuh di daerah tropis (tropical plant) dan memiliki jenis dengan jumlah yang sangat banyak tetapi masih belum dimanfaatkan secara optimal, sehingga memiliki kesempatan untuk dikembangkan sebagai bahan produk. Dengan pemahaman (1) sifat fisik dan morfologinya; (2) karakteristik coir fiber (serabut kelapa) sebagai salah satu serat alam yang dapat digunakan sebagai bahan produk yang mampu memenuhi kebutuhan aplikasi produk teknik belum menunjukkan hasil yang memuaskan. Agar bahan dapat digunakan maka dibutukan perlakuan serat agar dihasilkan sifat fisik dan kekuatan yang lebih baik. Berdasarkan kondisi tersebut maka dibuat produk pelindung yaitu produk body protector yang berasal dari coir fiber, dimana serabut kelapa memiliki karakteristik fisik yaitu kekuatan tarik, elastisitas, biodegradable, dan insulasi yang baik terhadap suhu. Dengan karakteristik tersebut maka dapat dilakukan proses biotreatmen. Proses awal dilakukan treatmen bio-scoring kemudian dilakukan proses bio-sizing yang dapat meningkatkan kualitas fisik serabut kelapa. Proses treatmen bio sizing menggunakan bahan latek, arrow root dan resin dan menghasilkan serabut kelapa nonwoven sehinga dapat digunakan menjadi produk body protector. Untuk mehasilkan produk body protector yang ergonomis maka dilakukan pengukuran antropometri pada orang dewasa dengan didapat hasil pengukuran. Peningkatan kualitas fisik coir fiber dengan metode bio sizing setelah mengalami treatmen menjadi MC berkisar antara 13,38\% sampai 17,2\% sedangkan MR berkisar antara 16,79\%, sampai 20,77\%, kekuatan 3,2 kg/mm sehingga dapat dijadikan produk body protector memiliki kualitas dan tingkat kenyamanan yang baik dengan disain ergonomis pengukuran antropometri dengan dimensi produk yang dirancang sesuai anthropometri untuk lebar bahu adalah terkecil $41 \mathrm{~cm}$ dan terbesar 46,5 cm, ukuran dimensi lebar dada terkecil $86 \mathrm{~cm}$ terbesar 101,5 cm dan ukuran dimensi panjang badan terkecil $61,6 \mathrm{~cm}$ terbesar $64,4 \mathrm{~cm}$
\end{abstract}

Kata Kunci : Coir Fiber, Bio-Treatment Sizing, Body Protector Ergonomis

\begin{abstract}
Natural fiber derived from coconut fiber grows in many tropical regions (tropical plant) and have the kind with the very large but still not used optimally, so having the opportunity to be developed as a product. With an understanding of (1) physical properties and morphology; (2) the characteristics of coir fiber (coconut fiber) as one of the natural fibers that can be used as a product that is able to meet the needs of the product application techniques have not shown satisfactory results. So that materials can be used in fiber treatment is needed in order to produce physical properties and strengths better. Under these conditions, the product is made of protective body protector is a product derived from coir fiber, coconut fibers which have physical characteristics that the tensile strength, elasticity, biodegradable, and good insulation against temperature. With these characteristics, it can do the process of biotreatments. The initial process is done treatments bio-scoring then conducted bio-sizing process that can improve the physical quality of coconut fibers. The process of bio sizing treatments using latex materials, arrow root and resin and produce nonwoven coconut fibers so that the product can be used as body protector. To produce ergonomic body protector product is carried out anthropometric measurements in adults with measurement results obtained. Improved physical quality of coir fiber with bio sizing method after experiencing an MC treatments ranged from $13.38 \%$ to $17.2 \%$ while the MR ranged from $16.79 \%$ to $20.77 \%$, the strength of $3.2 \mathrm{~kg} / \mathrm{mm}$ so that the product can be used as a body protector has quality and level of comfort with an ergonomic design with dimensional anthropometric measurements according anthropometry products designed for shoulder width $41 \mathrm{~cm}$ is the smallest and the largest of $46.5 \mathrm{~cm}$, the size of the smallest dimensions of $86 \mathrm{~cm}$ width of chest largest $101.5 \mathrm{~cm}$ and the size of the smallest body length dimension $61.6 \mathrm{~cm}$ and largest $64.4 \mathrm{~cm}$
\end{abstract}

Keywords: Coir Fiber, Bio-Treatment Sizing, Ergonomic Body Protector 


\section{PENDAHULUAN}

Seiring dengan maraknya berbagai isu tentang produk-produk yang ramah lingkungan serta tuntutan konsumen akan produk yang berkualitas mendorong kesadaran berbagai pihak untuk mulai bersahabat dengan lingkungan. Untuk mengurangi dampak negatif terhadap lingkungan bahan-bahan non plastic masyarakat telah memahami keuntungan dalam pemanfaatan bahan-bahan serat alam selulosa seperti kayu dan bambu sebagai bahan sandang, kertas, konstruksi bangunan dan alat rumah tangga, selulosa yang merupakan biopolymer berbasis agro (agro-based fiber) memiliki (a) sumber yang mampu diperbaharukan, (b) biodegradable, (c) mudah didapat, (d) mampu bentuk dan (e) multi fungsi [1]. Perkembangan material teknik terutama bahan-bahan baru (high-tech materials), proses manufaktur dan aplikasi teknik dekade ini menunjukkan peningkatan. Masalah yang timbul seiring dengan perkembangan teknologi bahan tersebut adalah bagaimana memanfaatkan bahan-bahan tersedianya cukup banyak yang mampu diregenerasikan untuk mengantisipasi krisis bahan terutama jenis serat sintetis dimana tersedianya sumber bahan dipengaruhi oleh sumber minyak bumi yang tidak bisa diperbaharui [2]. Salah satu pemecahan masalah adalah dengan memanfaatkan serat alam selulosa sebagai bahan campuran untuk menghasilkan bahan yang dapat digunakan seluas-luasnya untuk aplikasi teknik, baik struktur maupun non-struktur [3]. Keuntungan ini dilandasi oleh kenyataan bahwa serat alam, seperti sabut kelapa dapat menjadi salah satu alternatif. Kelebihan dari serat kelapa adalah kuat, elastisitas, tahan terhadap penguraian mikroba, tahan terhadap salinitas, biodegradable dan banyak tersedia di alam. Sabut kelapa terdiri atas lapisan luar (exocarpium) dan lapisan dalam (endocarpium). Limbah serat buah kelapa sangat potensial digunakan sebagai penguat bahan produk yang ramah lingkungan. Hal ini menarik untuk memanfaatkan serabut kelapa menjadi bahan produk untuk diaplikasikan pada suatu produk body protector yang ergonomis dan memiliki nilai tersendiri dan diminati oleh konsumen. Penelitian ini bertujuan untuk mendapatkan bahan alternatif produk body protector yang ergonomis dari serabut kelapa.

Pada dekade terakhir penggunaan sepeda motor di Indonesia semakin meningkat. Berdasarkan data dari Kakorlantas Polri, pada tahun 2012 jumlah sepada motor yang terdaftar adalah 77.755.658 unit, atau mengalami peningkatan sebesar $12 \%$ dari tahun sebelumnya. Jumlah ini merupakan yang terbanyak di antara negara-negara di Asia Tenggara (Kompas, 21/02/2013). Peningkatan penggunaan sepeda motor disebabkan karena kebutuhan masyarakat akan akomodasi dan juga meningkatkan efisiensi waktu.

Peningkatan jumlah pengguna sepeda motor berbanding lurus dengan jumlah kecelakaan yang terjadi. Data Kepolisian RI menyebutkan, pada 2012 terjadi 109.038 kasus kecelakaan. Berdasarkan data dari Korlantas, salah satu penyebab kecelakaan lalu lintas jalan khususnya sepeda motor paling banyak disebabkan oleh faktor Human error sebesar $67 \%$. Sedangkan faktor lainnya, kondisi jalan seperti rusak, bergelombang dan unsur lingkungan misalnya hujan mencapai 33\%. Lalu sisanya, seperti kendaraan tak layak jalan 3\%.

Kenyataannya, sebagian pengendara motor di Indonesia mengabaikan safety equipment saat berkendara, contohnya penggunaan pengaman yang sangat minim bagi pengendara motor di Indonesia. Baju pelindung tubuh sebenarnya sudah banyak tersedia di pasaran, Namun para pengguna sering mengabaikan karena harganya yang mahal, desain yang kurang ergonomis, fungsi protector-nya kurang kuat. Selain itu banyak konsumen yang merasa gerah atau tidak nyaman saat memakai. Oleh karena itu para pengguna motor lebih sering memakai jaket biasa pada saat berkendara, pemakaian pelindung atau body protector sangat minim saat berkendara.

Produk pelindung sebenarnya sudah banyak tersedia di pasaran, namun harganya relatif mahal, desain kurang ergonomis, bahan terbuat dari serat sintetis sehingga tidak ramah lingkungan. Berbeda dengan produk body protector yang terbuat dari bahan dasar coir fiber. Latar belakang permasalahan dapat diuraikan sebagai berikut, (1) Serat alam yang 
berasal dari coir fiber (serabut kelapa), yang tumbuh di Indonesia (tropical plant) memiliki jenis dan jumlah yang sangat banyak tetapi belum dimanfaatkan secara optimal, sehingga memiliki kesempatan untuk dikembangkan sebagai bahan produk melalui pemahaman sifat fisik dan morfologinya; (2) Karakteristik coir fiber (serabut kelapa) sebagai salah satu serat alam yang dapat digunakan sebagai bahan produk yang mampu memenuhi kebutuhan aplikasi teknik untuk komponen struktural belum menunjukkan hasil yang memuaskan [4]. Perlu dilakukan perlakuan serat agar dihasilkan sifat fisik dan kekuatan yang lebih baik [5]; (3) Penggunaan bahan plastik dalam jumlah yang besar yang berasal dari sumber minyak bumi suatu saat akan mengalami krisis minyak dengan berkurangnya pasokan bahan baku senyawa hidrokarbon. Hal ini mendorong pemanfaatan bahan-bahan yang berasal dari alam sebagai produk dengan treatment bio scouring. Dari uraian fakta tersebut penelitian bertujuan untuk membuat produk body protector yang didisain mengikuti kaidah ergonomis, dan desain menggunakan bahan dari coir fiber, atau yang kita sebut sebagai sabut kelapa. Dari kekuatan standar yang dihasilkan, body protector ini bisa digunakan untuk pacuan kuda maupun freestyle (sktateboard, sepatu roda, motor dan lain-lain) serta dapat pula digunakan untuk balap drag bike dan motor cross. Jadi, fungsi produk body protector ini beragam. Penelitian ini mempunyai tujuan untuk:

1. Mendeskripsikan dan menganalisis kualitas serat serabut kelapa terhadap pengaruh biosizing agar tercapai kualitas serat serabut kelapa.

2. Meningkatkan kualitas serat

3. Merancang disain produk body protector sesuai kajian ergonomic ukuran antropometri.

Coir fiber merupakan serat serabut kelapa yang berasal dari kulit buah kelapa dimana pemanfatan serabut kelapa belum optimal maka perlu dilakukan treatment sehingga akan meningkatkan serat tersebut. Proses awal dalam pengolahan serat serabut kelapa agar dapat digunakan menjadi produk body protector adalah memerlukan dua tahap pengolahan yakni (a). proses pencabikan dan pesejajaran serabut kelapa dan hasilnya akan menentukan kualitas serat (b). proses perlakuan kimia yang bertujuan melepaskan zat-zat getah lapisan lilin dan pektin dari serat yang disebut proses treatment.

Coir fiber (Sabut kelapa) merupakan bagian terluar buah kelapa yang membungkus tempurung kelapa. Ketebalan sabut kelapa berkisar 5-6 cm yang terdiri atas lapisan terluar (exocarpium) dan lapisan dalam (endocarpium).

Endocarpium mengandung serat-serat halus yang dapat digunakan sebagai bahan pembuat tali, karung, pulp, karpet, sikat, keset, isolator panas dan suara, filter, bahan pengisi jok kursi mobil dan papan hardboard. Satu butir buah kelapa menghasilkan 0,4 kg sabut yang mengandung 30\% serat. Komposisi kimia sabut kelapa terdiri atas selulosa, lignin, pyroligneous acid, gas, arang, ter, tannin, dan potasium [6].

Keunggulan coir fiber (1) anti Ngengat; tahan terhadap jamur dan membusuk, (2) memberikan insulasi yang sangat baik terhadap suhu dan suara, (3) tidak mudah terbakar (4) alot dan tahan lama,(5) resilient; mata kembali ke bentuk konstan bahkan setelah digunakan, (6) totally statis, (7) mudah dibersihkan, (8) kekutan lebih lama, (9) sabut Geotextiles adalah $100 \%$ bio-degradable dan ramah lingkungan.

\section{A. Kualitas Serabut kelapa}

Kualitas serat antara lain meliputi moiusture regain, kekuatan tarik serat. Kekuatan adalah merupakan salah satu sifat bahan yang sangat penting, karena kekuatan bahan akan berpengaruh pada hasil produk yang dibuat, antara lain berpengaruh pada twist, kerataan, distribusi panjang serat dan pengerjaan akhir serat woven atau non woven [5].

Pada prinsipnya terdapat dua macam jenis pengujian kekuatan bahan yakni a).pengujian kekuatan tarik dan mulur woven dan b). pengujian kekuatan tarik non woven.

\section{B. Biotreatment Sizing}

Salah satu cara mengoptimalkan serat alam adalah dengan perlakuan yang disebut biotreatment yaitu dengan menggunakan proses 
scouring dan sizing. Scouring merupakan proses penghilangan kotoran dan lapisa lilin yang ada pada serat sehingga dapat menyebabkan kualitas dari serat atau bahan material. Sizing juga merupakan proses treatment yang sudah dikenal di kalangan industri tekstil yakni proses pengolahan serat yang akan dipintal menjadi benang dan ditenun menjadi kain. Sizing merupakan suatu proses pemberian lapisan pada bahan untuk melapisi benang-benang lusi dengan campuran kimia tertentu agar benang-benang tersebut mampu ditenun dengan baik sesuai dengan hasil yang diharapkan. Proses sizing bertujuan untuk mempersiapkan benang agar kuat, tahan gesek, lentur dan mampu ditenun pada kecepatan tinggi dan density tinggi sesuai kualitas yang diharapkan. Serat yang telah dikenai perlakuan treatment akan memberikan pengaruh terhadap kehalusan, kekuatan dan kemampuan proses tenun yang optimal. Bahan proses bio sizing yaitu menggunakan yang ramah lingkungan dan memiliki kompatibilitas dengan serat alam berbasis selulosa terutama untuk penggunaan lanjut. Media treatment alam atau bio-treatment yang digunakan untuk mengoptimalkan sifat serat alam.

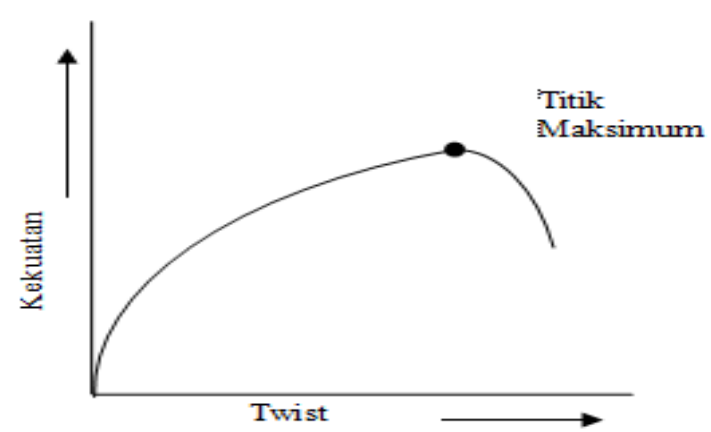

Gambar 1. Hubungan Antara Kekuatan Tarik dengan Twist

\section{Body Protector}

Body protector merupakan pelindung bagi pengendara kendaraaan bermotor. Body protector sangat berguna dalam meminimalisasi cedera jika terjadi kecelakaan. Namun masih banyak pengendara sepeda motor menganggap sepele penggunaan body protector saat riding. Dengan alasan yaitu merepotkan dan tidak nyaman. Sesungguhnya body protector dirancang untuk melindungi tubuh. Sehingga kita dapat menghargai dan merawat tubuh kita lebih dini untuk menghindari dari terjadinya patah tulang akibat kecelakaan, degeneratif, osteoporosis, atau penyakit lainnya.

Pelindung tubuh yang ditandai dengan konstruksi rapat pada pakaian tertentu, dengan bahan canggih difokuskan pada perlindungan tubuh terhadap dampak, seperti jatuh. Konstruksi dan bahan mempengaruhi perpindahan panas antara tubuh manusia dan lingkungan, dan menambah beban ekstra untuk produksi panas metabolik pengendara yang telah meningkat dengan melakukan sifat termal pelindung tubuh berdasarkan busa konvensional, pada kain spacer, dan kombinasi dari kedua telah diukur dan dievaluasi. Selain itu, Transplanar tester transportasi air yang digunakan untuk menilai sifat transportasi cairan dari bahan pelindung yang diterapkan. Hasil penelitian mendukung kegunaan dari warp-rajutan kain spacer dalam pakaian dampak-pelindung radiasi [7]. Pakaian pelindung di lingkungan yang panas dan regangan panas pada pria dari berbagai usia 38 . Aspek menerapkan dan evaluasi Badan Balistik Armours Menggunakan Balistik Rompi [8]. Efek gabungan dari absorbansi kelembaban kain dan permeabilitas udara pada thermophysiological di lingkungan yang hangat. Evaluasi persyaratan perlindungan lingkungan dingin disarankan agar nilai isolasi termal dari cebol thermal bergerak dapat digunakan untuk persyaratan Pakaian pelindung yang digunakan untuk mencapai keselamatan bagi orang-orang lingkungan profesional dan lainnya. Keselamatan didefinisikan bebas dari risiko bahaya yang tidak dapat diterima (ISO,1986). Langkah-langkah untuk mencapai keselamatan dapat dibagi menjadi tiga tingkatan:yaitu (1). Proses, peralatan dan produk harus dibuat aman, yang berarti harus dipahami sedemikian rupa bahwa setiap risiko bahaya dipisahkan dari orang-orang yang terlibat. (2). Setiap orang tetap harus menghindari dengan sumber risiko, walaupun mereka telah dilindungi oleh peralatan pelindung yang sesuai. (3). Untuk menghindari orang-orang terkena risiko maka perlu menempatkan tanda peringatan di depan sumber risiko. Dari konsep ini kita dapat melihat bahwa penggunaan pakaian pelindung 
jelas bukan yang pertama pilihan di antara langkah-langkah keamanan. Pengembangan teknis dan tren, ukuran dan pakaian pelindung dari semua jenis semakin sangat penting di masa depan dalam pekerja di bidang rekreasi dan olahraga [9].

\section{Disain Ergonomi dengan Anthropemetri}

Menurut Stevenson, anthropometri dibagi menjadi dua bagian antara lain: (1). Anthropometri statis yaitu pengukuran dilakukan pada saat tubuh dalam keadaan diam. mencakup pengukuran tubuh, baik berupa kepala, dada, kaki dan lain-lain dalam ukuran standar, (2). Anthropometri dinamis yaitu dimana dimensi tubuh yang diukur mencakup pengukuran yang dilakukan dalam posisi kerja atau posisi tubuh yang sedang bergerak. Dimensi yang diukur pada anthropometri statis diambil secara linier (lurus) dan dilakukan pada permukaan tubuh, agar hasilnya representatif maka pengukuran harus dilakukan dengan metode tertentu terhadap individu. Manusia pada umumnya akan berbeda-beda dalam hal bentuk dan dimensi ukuran tubuhnya [10].

Dalam konteks kendaraan bermotor, maka digunakan untuk mendesain senyaman mungkin pada saat berkendara. Yang sering diketahui mungkin titik segitiga kendaraan; pijakan kaki, posisi duduk, dan jarak handle stang dengan tangan.

\section{A. Bahan dan Alat}

\section{METODOLOGI PENEITIAN}

Bahan Utama serat serabut kelapa terdiri dari jenis: serabut kering/mentah, web, sliver, halus/sisir.

Sebelum mengalami proses biotreatment sizing, diperlukan proses bio scouring dengan bahan yang digunakan: serabut kelapa, klerek, asam cuka, kaporit, sedangkan bahan untuk biotreatment sizing adalah: (1) Serabut kelapa, (2) tepung larut/arrowt, (3) Latex, (4) Gel (pembatas cetakan), (5) Talc, (6) Silicon (buat cetakan duplikasi), (7) Katalis (pengeras), (8) Resin.

Bahan tambahan yang digunakan adalah: (1) Kain dari kulit digunakan sebagai pelapis Body Protector. Dengan disain plaint sehingga sirkulasi udara mampu memberikan efek tidak panas. Dan mempunyai sifat sifat yang meliputi: Tidak mudah berubah bentuk (berkerut), aman bersentuhan dengan kulit, anti air dan anti angin, elastis, (2) busa sebagai sejenis koloid. Kerapatan yang rendah membuat busa-busa padat digunakan sebagai penyekat/ isolasi termal, (3) spon foam digunakan sebagai bantalan dalam body protector dengan karakteristik karet cukup sedikit dan elastis sehingga cocok di gunakan sebagai pelapis body protector.

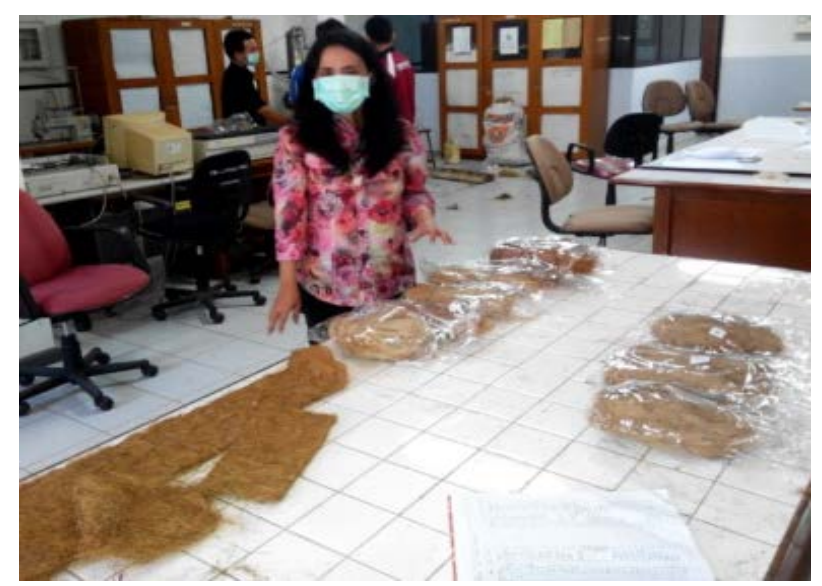

Gambar 2. Bahan Serabut Kelapa

Alat yang digunakan dalam penelitian ini adalah: (1) Oven listrik (2) Timbangan digital, (3) Termometer digital (4) Gelas pemasak, (5) Mesin uji tarik (6) Mikroskop optik.
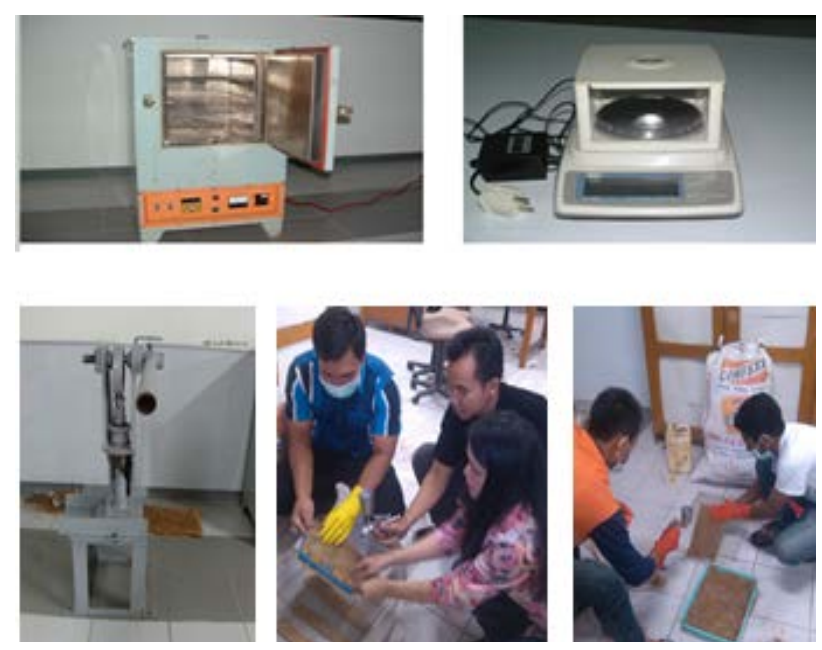

Gambar 3. Contoh Alat Utama Untuk Penelitian

\section{B. Proses dan Pengujian Kualitas Serat}

Proses dan pengujian terbagi dalam dua tahapan secara rinci tiap tahapan diuraikan sebagai berikut: 
(a) Tahap awal serat serabut kelapa (coir fiber) dilakukan identifikasi. Secara serempak media bio treatmen souring yaitu dengan menggunakan klerek, asam cuka dan kaporit dan dilakukan pada suhu 50, 70, 100 setelah diproses diuji kandungan mouistuter content dan mouisture regain dan di uji kekuatan tarik sebelum dan sesudah dilakukan treatmen scouring untuk mengidentifikasi media biotreatment dan hasil perlakuan tersebut. Pengujian muoisture regain dilakukan sebelum dan proses bio tratment. Pengujian kekuatan tarik dan mulur sebelum perlakuan biotreatment

(b) Selanjutnya dilakukan proses pembuatan serabut kelapa non woven dengan menggunakan proses bio sizing yaitu melapisi bahan serabut kelapa dengan latek dibuat lembaran serabut kelapa dan dilakukan proses. Kegiatan dilanjutkan dengan menganalisa struktur lembaran dan non woven dan melakukan pengujian kualitas serabut kelapa setelah mengalami biotreatment dan menentukan kualitas bahan yang mampu diprediksi memberikan fungsi kualitas produk. Hasil diamati dengan mikroskop. Pembuatan Produk body protector dengan mengaplikasikan disain ergonomis antropometri

\section{HASIL DAN PEMBAHASAN \\ Kandungan Air Dalam Serat}

Kandungan air dalam serat dinyatakan dengan Mouisture Content dan Mouisture Regain (MC dan MR). Dari hasil penelitian pemakaian biotreatment mendapatkan perubahan nilai MC dan MR sebelum dilakukan treatment adalah jenis serat mentah, MC 11,26\% dan MR 12,29\%, jenis serat web MC $12,92 \%$ dan MR 14,84\%, jenis serat silver MC 12,8\% dan MR 14,67\%, jenis serat halus/sisir MC 13,11\% dan MR 15,11\%.

Serabut kelapa dilakukan bio treatment dengan menggunakan klerek maka didapatkan kandungan air jenis serat mentah, MC 13,56\% dan MR 15,57\%, jenis serat web MC 13,92\% dan MR 16,23\%, jenis serat serat silver MC 15,12\% dan MR 17, 81\%, jenis serat halus/sisir MC 17,2\% dan MR 20,77\%.
Serabut kelapa dilakukan bio treatment dengan menggunakan asam cuka maka didapatkan kandungan air jenis serat mentah, MC $12,72 \%$ dan MR 14,57\%, jenis serat web MC 14,24\% dan MR 16,04\%, jenis serat silver MC 14,38\% dan MR 16,79\%, jenis serat halus/sisir MC 15,02\% dan MR 17,67\%.

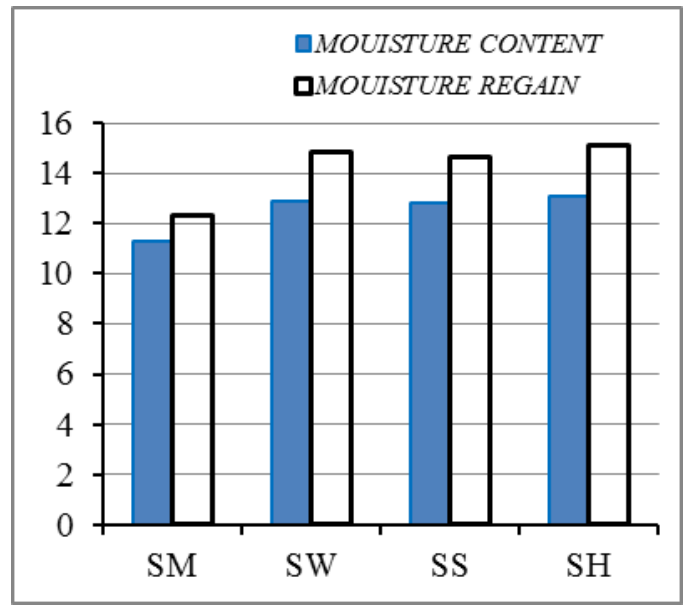

Gambar 4. Data Kandungan Air Sebelum Treatment

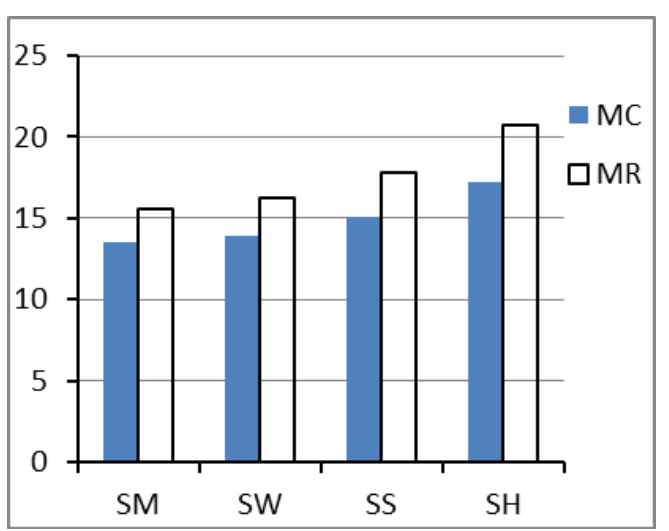

Gambar 5. Data Kandungan Air Treatment Klerek

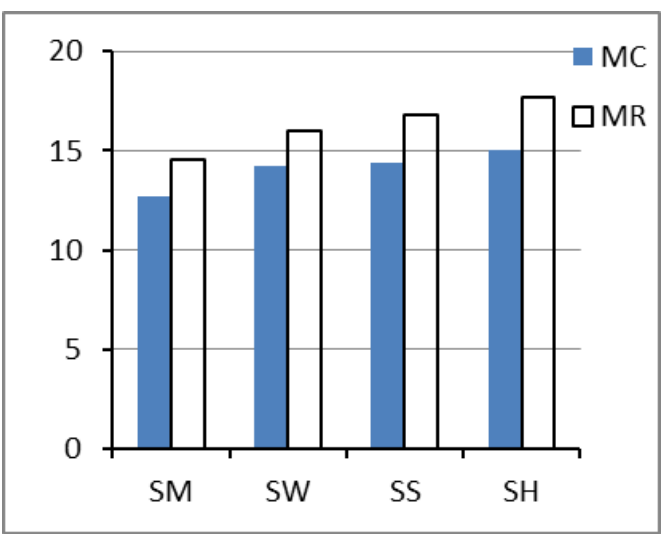

Gambar 6. Data Kandungan Air Treatment Asam Cuka 
Serabut kelapa dilakukan bio treatment dengan menggunakan kaporit maka didapatkan kandungan air jenis serat mentah, MC 13,64\% dan MR 15,79\%, jenis serat web MC 13,52\% dan MR 15,63\%, jenis serat silver MC 12,62\% dan MR 14,39\%, jenis serat halus/sisir MC 14,38\% dan MR 16,79\%.

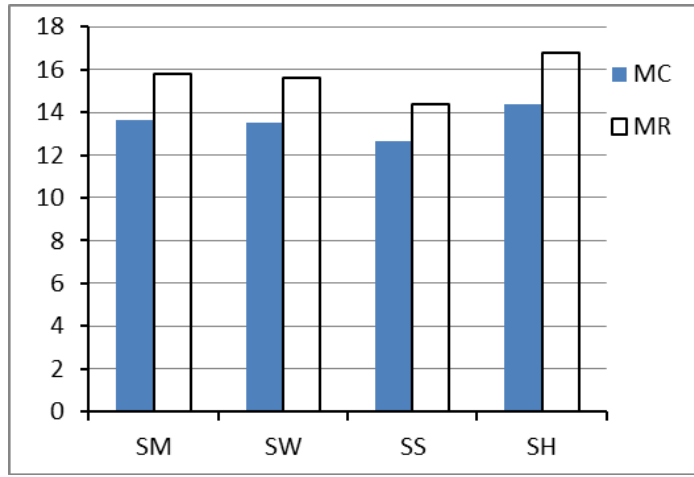

Gambar 7. Data Kandungan Air Treatment Kaporit
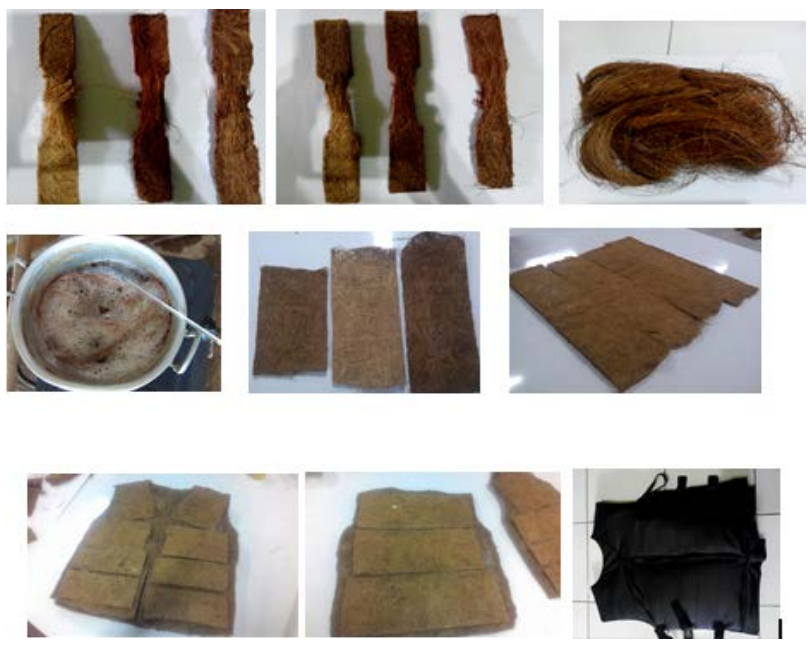

Gambar 8. Hasil Bahan Tahapan Proses Biotreatment

Disain Ergonomi Pengukuran Anthropometri

Untuk mengimplementasikan serabut kelapa sebagai bahan body protector rancangan disain berdasarkan prinsip anthropometri. Dalam pengumpulan dan pengolahan data sampel yang digunakan tingkat kepercayaan 95\% (K=2) dan tingkat ketelitian (s) 5\%, dengan asumsi bahwa berdasarkan kondisi tempat pengambilan data, maka kebenaran yang diharapkan 95\% dan hanya terdapat 5\% data yang menyimpang dari data-data sebenarnya. Data-data anthropometri yang digunakan dalam perancangan rompi ini adalah : (1) Lebar Bahu, (2) Lebar Dada, (3) Panjang Badan.

\section{LebarBahu}

Lebar bahu diukur dari jarak bahu kanan kekiri, yang akan digunakan sebagai lebar bahu body protector.

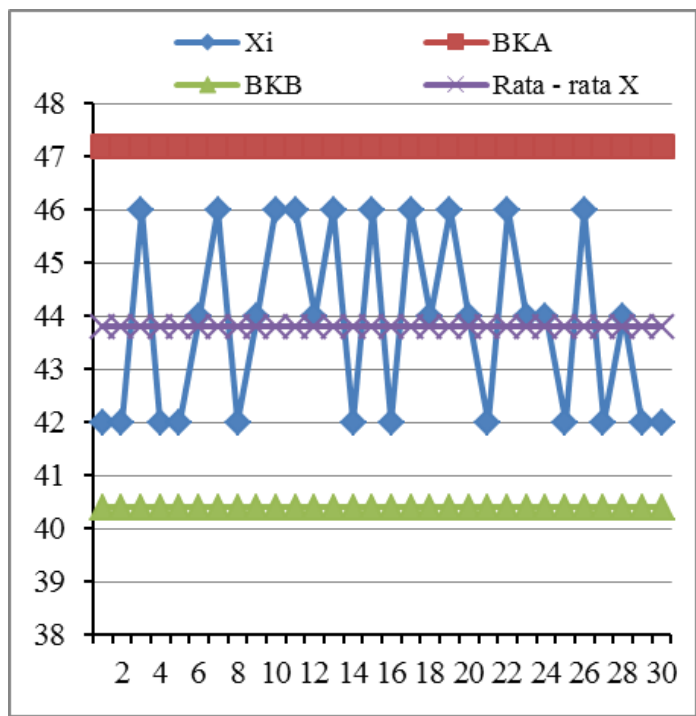

Gambar 9. Grafik Lebar Bahu

Pada Gambar 9 grafik peta kendali lebar bahu didapat nilai rata-rata lebar dada dengan rincian :

Rata-rata nilai $\mathrm{X}=\sum_{i-1}^{n} \frac{X_{i}}{n}$

Rata-rata nilai $X=\frac{1316}{30}$

Rata-rata nilai $X=43,87 \mathrm{~cm}$

Standar deviasi $\sigma=\sqrt{\frac{N\left(\sum X i 2\right)-\left(\sum X i\right) 2}{N^{2}}}$

Standar deviasi $\sigma=\sqrt{\frac{30(1316) 2-(1316) 2}{30(30)}}$

Standar deviasi $\sigma=\sqrt{2.92}$

Standar deviasi $\sigma=1,7 \mathrm{~cm}$

Batas Kendali Atas (BKA)

Rata-rata nilai $X+2 \sigma_{x}$

$$
X+2 \sigma_{x}=47,2 \mathrm{~cm}
$$

Batas Kendali Bawah ( BKB )

Rata-rata nilai $X-2 \sigma_{x}$

$$
X-2 \sigma_{x}=40,4 \mathrm{~cm}
$$

Dari hasil perhitungan tersebut didapat hasil bahwa :

Banyaknya data $(\mathrm{N})=30$ 
$\begin{array}{ll}\text { Data terbesar } & =46 \mathrm{~cm} \\ \text { Data terkecil } & =42 \mathrm{~cm}\end{array}$

Jumlah data keseluruhan $=\left(\sum \mathrm{X}_{i}\right)=1316 \mathrm{~cm}$

Jumlah data keseluruhan dikuadratkan

$$
\begin{array}{ll}
\left.\qquad \sum \mathrm{X}_{i}\right) & =57816 \\
& =43,8 \mathrm{~cm} \\
\text { Rata-rata data } & =1,7 \mathrm{~cm}
\end{array}
$$

Berdasarkan uji keseragaman data bahwa data lebar bahu seragam dan masih dalam batas control antara 40,4 cm sampai dengan 47,2 cm. Dari perhitungan persentil 5\% terhadap ukuran anthropometri lebar bahu diperoleh ukuran 41 $\mathrm{cm}$ yang menggambarkan ukuran anthropometri lebar bahu terkecil adalah $41 \mathrm{~cm}$ dengan 5\% populasi akan berada pada atau di bawah ukuran tersebut. Sedangkan dari perhitungan persentil 95\% diperoleh ukuran 46,5 cm yang menggambarkan ukuran anthropometri lebar bahu terbesar adalah 46,5 cm dengan $95 \%$ populasi akan berada pada atau di bawah ukuran tersebut.

\section{Lebar Dada}

Lebar dada diukur yaitu lingkar dada kanan dan kiri, yang akan digunakan sebagai lebar dada body protector.

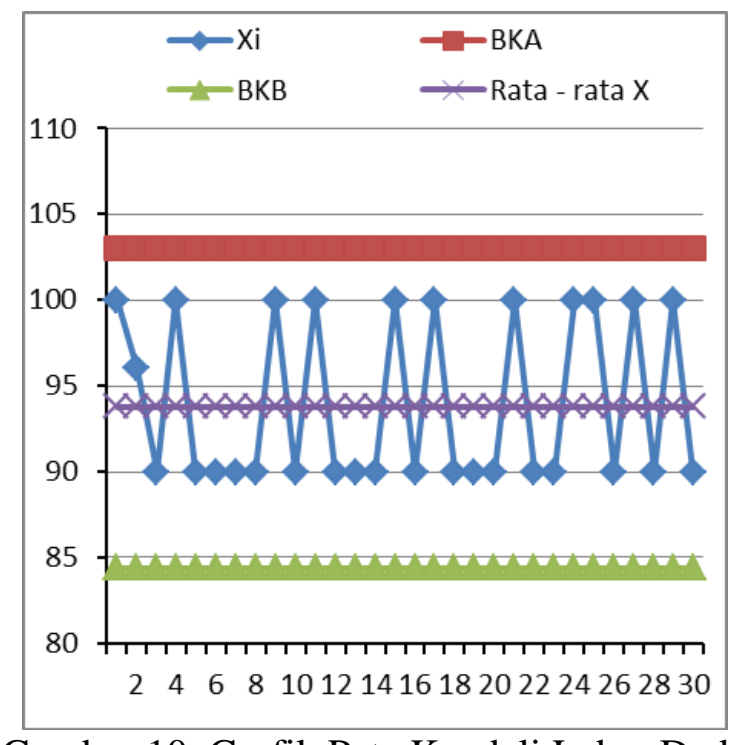

Gambar 10. Grafik Peta Kendali Lebar Dada

Pada Gambar 10 grafik peta kendali lebar dada didapat nilai rata-rata lebar dada dengan rincian :

rata-rata $\mathrm{X}=\frac{\sum X i}{n}$

$$
\begin{aligned}
& =\frac{2816}{30} \\
& =93,8 \mathrm{~cm}
\end{aligned}
$$

Standar deviasi $\sigma=\sqrt{\frac{\mathrm{N}\left(\sum \mathrm{Xi} 2\right)-\left(\sum \mathrm{Xi}\right) 2}{\mathrm{~N}^{2}}}$

Standar deviasi $\sigma=\sqrt{\frac{30(265016)-(2816) 2}{900}}$

Standar deviasi $\sigma=\sqrt{\frac{7950480-7929856}{900}}$

Standar deviasi $\sigma=\sqrt{22,92}$

Standar deviasi $\sigma=4,7 \mathrm{~cm}$

Batas Kendali Atas (BKA)

Rata-rata nilai $X+2 \sigma_{x}=103 \mathrm{~cm}$

Batas Kendali Bawah $(\mathrm{BKB})=$

Rata-rata nilai $X-2 \sigma_{x}=84,4 \mathrm{~cm}$

Dari hasil perhitungan tersebut didapat hasil bahwa :
Banyaknya data $(\mathrm{N})=30$
Data terbesar $\quad=100$
Data terkecil $\quad=90$

Rata-rata data sebesar $93,8 \mathrm{~cm}$

Standar deviasi $(\sigma)=4,7 \mathrm{~cm}$

Berdasarkan uji keseragaman data bahwa data lebar dada seragam dan masih dalam batas control antara 84,4 cm sampai dengan $103 \mathrm{~cm}$. Dari perhitungan persentil 5\% terhadap ukuran anthropometri lebar dada diperoleh ukuran 86 $\mathrm{cm}$ yang menggambarkan ukuran anthropometri lebar dada terkecil adalah $86 \mathrm{~cm}$ dengan $5 \%$ populasi akan berada pada atau di bawah ukuran tersebut. Sedangkan dari perhitungan persentil 95\% diperoleh ukuran 101,5 cm yang menggambarkan ukuran anthropometri lebar dada terbesar adalah 101,5 cm dengan $95 \%$ populasi akan berada pada atau di bawah ukuran tersebut.

\section{Panjang Badan}

Panjang badan diukur vertical dari jarak bahu ke pinggul, yang akan digunakan sebagai panjang body protector.

$$
\begin{aligned}
\text { Nilai rata }- \text { rata } X & =\frac{\sum X i}{n} \\
& =93,8 \mathrm{~cm} \\
\text { Standat deviasi } \sigma= & \sqrt{\frac{\mathrm{N}\left(\sum \mathrm{Xi} 2\right)-\left(\sum \mathrm{Xi}\right) 2}{\mathrm{~N}^{2}}}
\end{aligned}
$$


$\begin{aligned} \text { Standar deviasi } \sigma & =\sqrt{\frac{30(265016)-(2816) 2}{900}} \\ \text { Standat deviasi } \sigma & =\sqrt{\frac{7950480-7929856}{900}} \\ \text { Standar deviasi } \sigma & =\sqrt{22,92} \\ \text { Standar deviasi } \sigma & =4,7 \mathrm{~cm}\end{aligned}$

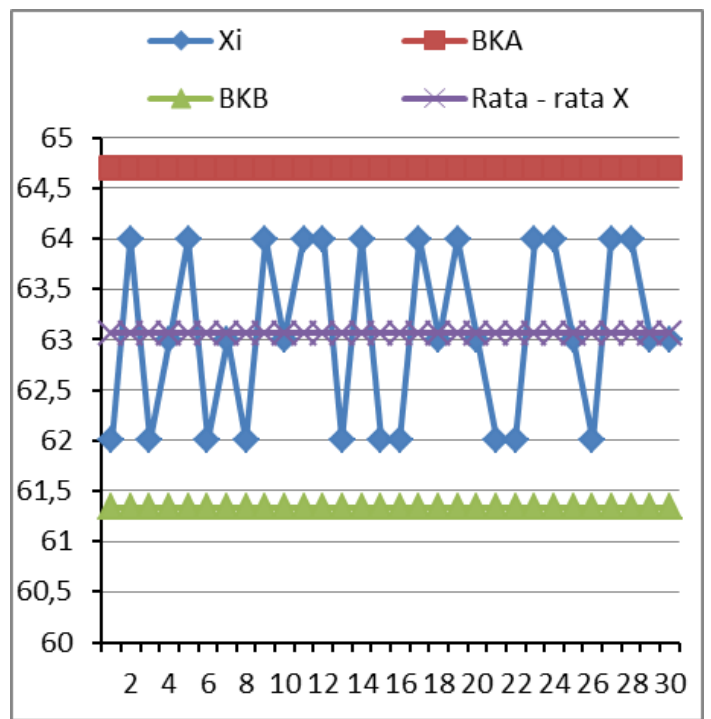

Gambar 11. Grafik Peta Kendali Panjang Dada

Batas Kendali Atas (BKA)

$\mathrm{BKA}=$ Rata-rata nilai $\mathrm{X}+2 \sigma_{\mathrm{X}}=93,8+2 \times 4,7$

$=103 \mathrm{~cm}$

Batas Kendali Atas (BKB)

$\mathrm{BKB}=$ Rata-rata nilai $\mathrm{X}-2 \sigma_{\mathrm{x}}=93,8-2 \times 4,7$ $=84,4 \mathrm{~cm}$

\section{KESIMPULAN}

Dengan menggunakan metode bio treatment maka dapat meningkatkan kualitas apabila mengalami proses biotreatment maka akan meningkatkan kualitas serabut kelapa non woven . Dari hasil penelitian dapat disimpulkan sebagai berikut nilai Moisture content dan moisture regain mengalami peningkatan kualitas fisik coir fiber dengan metode bio sizing setelah mengalami treatment menjadi MC berkisar antara 13,38\% sampai 17,2\% sedangkan MR berkisar antara 16,79\%, sampai 20,77\%, pada pengujian impact serabut kelapa jenis sisir mempunya rata-rata energi bahan: 0,302 Joule dan harga impact $0,0034 \mathrm{~J} / \mathrm{mm}$. Ukuran dimensi produk yang dirancang sesuai anthropometri untuk lebar bahu adalah terkecil $41 \mathrm{~cm}$-terbesar $46,5 \mathrm{~cm}$, ukuran dimensi lebar dada terkecil $86 \mathrm{~cm}$ terbesar 101,5 cm, dan ukuran dimensi panjang badan terkecil 61,6 cm terbesar 64,4 cm. Penelitian ini masih dapat dilanjutkan sebagai sebagai produk body protector karena memiliki MC dan MR yang baik sehingga akan menjadi lebih ergonomis dan nyaman dipakai

\section{UCAPAN TERIMA KASIH}

Ucapan terima kasih kepada DP2M Direktoral Jendral Pendidikan Tinggi Kementerian Riset Teknologi dan Pendidikan Tinggi Republik Indonesia atas pembiayaan penelitian melalui dana hibah bersaing tahun anggaran 2015 sehingga dapat terwujut artikel ini.

\section{DAFTAR PUSTAKA}

[1]. Muller, D.H., Krobjilowski, A., 2003, "New Discovery in the Properties of Composite Reinforced with Natural Fibers", Journal of Industrial Textiles, vol.33, no.2, pp.111-130 Sage Publ.

[2]. Marsahyo E., Soekrisno, Jamasri, Rochardjo H.S.B., 2005. "Kajian Mikromekanika Bahan Komposit Serat Ramie-Epoxy”, Disertasi Doktor (dalam proses penyelesaian), UGM, Yogyakarta.

[3]. Sedelnik, N., 2004, "Properties of Hemp Fibre Cottonised by Biological Modification of Hemp Hackling Noils", Fibres and Textiles in Eatern Europe, vol. 12, no. 1, pp.58-60.

[4]. Santafe Jr HPG, Da Costa LL, Rodriguez RJS, Lopes FPD, Monteiro SN. 2010, "Mechanical behavior of epoxy composites reinforced with acetylationtreated coir fibers”. In: TMS annual meeting. p. 335-42.

[5]. Wielage,B., Lampke, T., Utschick, H., Soergel, F., 2003, "Processing of Natural Fibre Reinforced Polymers and the Resulting of Dynamic-Mechanical Properties”, Journal of Materials Processing Technology, vol. 139, hal. 140-146, Elsevier.

[6]. Wie W, Gu H. 2009, "Characterisation and utilization of natural coconut fibres composites. Materials and Design”;30:2741-4. 
[7]. Dlugosch, Sabine; Hong Hu; Allan CK Chan, 2012, Impact Protective Clothing in Sport: Areas of Application and Level of Utilization, Research Journal of Textile \& Apparel; Vol. 16 Issue 3, p18

[8]. Anna Marszalek, Maria Konarska, Juhani Smolander, Krzysztof Soltynski, Andrzej Sobolewski, (2000), Radiation protective clothing in a hot environment and heat strain in men of different ages, Proceedings of nokobetef 6 and 1st European Conference on Protective Clothing held in Stockholm, Sweden
[9]. Traugott Zimmerli (2000), EMPA Swiss Federal Laboratories for Materials Testing and Research, CH-9014 St.Gallen, Switzerland

[10]. Stevenson, M.G., 1989, Principles of Ergonomics. Center for Safety ScienceUniversity of NSW, Australia 